\title{
Workplace risk management in the context of the covid-19 pandemic
}

\author{
Andrada Denisa Băbuț $^{1 *}$, Marius Simion Morar ${ }^{1}$, Cristian Raul Cioară ${ }^{1}$ and Cristian \\ Tomescu $^{l}$
}

${ }^{1}$ National Institute for Research and Development in Mine Safety and Protection to Explosion INSEMEX, 32-34 G-ral Vasile Milea Street, Petrosani, Hunedoara, Romania

\begin{abstract}
In March 2020, a pandemic was declared internationally, caused by a new coronavirus called COVID-19. With the advent of the COVID-19 virus and the declaration of the pandemic, safety and distancing measures have been instituted, which we cannot say we are used to and which we easily accept, but which are necessary to combat the spread of the virus. We also cannot deny that this pandemic has affected and continues to affect our mental health, triggering a certain state of anxiety and with it the lowering of our immune system, which makes us more vulnerable to disease. Paradoxically, mental health is one of the first things that helps us to resist and survive the crisis, which is why it is important to provide employees with protection to ensure the necessary mental comfort at work.

In this context, this paper synthesizes the basic principles and best practices of psychosocial risk assessment, highlighting how hazard identification and risk management strategies should be based on the involvement of all stakeholders in combating anxiety at workplace.
\end{abstract}

\section{Short presentation of COVID-19 virus}

COVID-19 virus, also known as Acute Respiratory Syndrome 2019-nCoV, Severe Acute Respiratory Syndrome 2 and Wuhan Pneumonia, is a viral respiratory syndrome caused by Severe Acute Respiratory Syndrome Coronavirus 2 (SARS-CoV-2). This is the syndrome involved in the coronavirus pandemic that broke out in 2019. [1]

According to WHO, the most common symptoms of COVID-19 are fever, fatigue and dry cough. Some patients may have sore throat and other pain, stuffy nose, runny nose, diarrhea. These symptoms are usually mild and appear gradually. Most people infected with COVID-19 have mild symptoms and recover without the need for special treatment. However, some face more severe illnesses and may require hospital care. The risk of severe symptoms increases with age, as do people with a weakened immune system and those suffering from chronic diseases such as diabetes, heart disease and lung disease. [2]

Some people who become infected do not develop any symptoms, as they are asymptomatic. About 1 in 6 people with COVID-19 becomes seriously ill and has difficulty breathing. The elderly, as well as those with underlying medical problems, such as high blood pressure, heart problems or diabetes, are more likely to develop a severe form. About $2 \%$ of people suffering from this disease have died. People with fever, cough and difficulty breathing should seek medical attention. People can get COVID-19 from others who have

*Andrada Denisa Băbuț: andrada.babut@insemex.ro 
the virus. The disease can be transmitted from one person to another through secretions in the form of small drops, which are spread when the infected person coughs or sneezes. These drops are placed on the surrounding objects and surfaces. Other people get COVID19 by touching these objects or surfaces, then touching their eyes, nose or mouth. People can also get COVID-19 if they breathe directly into the secretions spread by an infected person who coughs or sneezes. This is why it is important to keep a distance of at least 1 meter from a sick person. [3]

The COVID-19 vaccine is currently a tool of major importance in helping to control the pandemic, along with effective testing and compliance. [4]

Scientists estimate that an immunization of between $70 \%$ and $85 \%$ of the population is needed for things to return to normal. Some countries are making much faster progress than others, but so far, the vaccine has only been administered about to 120 million people worldwide.

Vaccinations protect against COVID-19, but if only a few people in a community get vaccinated, the virus can continue to spread uncontrollably. As more people receive the vaccine, the so-called "herd immunity" is gradually realized. [5]

COVID-19 Vaccines and complication management:

- Many vaccines are currently under trial

- Although the efficacy of the vaccines differs, they are comparable in reducing hospitalization and mortality

- Some vaccines had rare but fatal side effect reports.

- One of them is the AstraZeneca vaccine widely administered in our country

- The currently available vaccines may not be effective to new variants of the virus

- None of the vaccines were currently approved for pediatric use

- Currently no data on interchangeability of one vaccine with other COVID-19 vaccines $[13]$

\section{Stress and anxiety during the COVID-19 pandemic}

The rate of spread of the virus and high global COVID-19 mortality rate may explain the fear of contact with potentially infected people. Many studies confirm the strong impact that the threat of the new coronavirus disease (COVID-19) has on individuals. Such strong emotions trigger both physiological and psychological reactions.[15]

Despite its small size (measured in nanometer), its influence is great enough in triggering stress. As various countries declare a state of Emergency, restricted movement order and lockdown, varying reactions like sorrow, anxiety, misperception and fear have been ignited in the society. All of these have cumulatively caused stress among them.[16]

The COVID-19 pandemic and the imposition of strict but necessary measures to prevent the spread of the new coronavirus have been and still are a major stressor for both adults and children and adolescents.

During an epidemic of infectious diseases, stress can manifest itself in the following conditions, according to experts from the Center for Disease Prevention and Control in the United States (CDC):

- Fear and anxiety about one's own health and the health of loved ones;

- Changes in sleep or eating habits;

- Difficulty sleeping or concentrating;

- Worsening of chronic health problems;

- Excessive use of alcohol, tobacco or medications.

The above states and behaviors are perfectly normal in the event of a significant challenge. 
With the onset of the state of emergency, there have been rapid and major changes in our way of life, such as the postponement of classes and social gatherings, the change of work, the cancellation of holidays, shows, concerts and festivals. All these measures have given rise to intense and varied conditions, generated especially by the uncertainty that still looms over the new coronavirus.

People are naturally concerned about the health and safety of themselves and their loved ones, and it is important to recognize the seriousness of the challenge posed by the COVID19 pandemic and to be aware that fear and panic are usually unnecessary, especially in the long run. Caring for our well-being in times like this can help reduce stress and is crucial to enable us to continue to take calm and effective action in the midst of this global crisis.

Useful signs in recognizing stress and anxiety:

- Changes in sleep or food pattern (insomnia, frequent awakenings, poor sleep, loss of appetite or overeating);

- Excessive anxiety;

- Irritability;

- Panic attacks;

- Excessive use of alcohol, tobacco or drugs. [7, 8]

\section{The negative impact caused by the pandemic on employees}

Scientists have found that people around the world are struggling with high levels of anxiety and depression at work because of COVID-19. [6] Following an opinion poll on the effects on employees of these social changes and restrictions imposed by the pandemic, it is found that the level of anxiety and continuous stress severely affects their ability to perform their daily activities at work.

- Employees were more stressed and anxious at work in 2020 than in any other year.

- This increase in the level of stress and anxiety had a negative impact on the mental health of $70 \%$ of employees, causing more stress $(38 \%)$, a lack of work-life balance (35\%), exhaustion (25\%), depression due to lack of socialization $(25 \%)$ and loneliness (14\%).

- The new pressures generated by the global pandemic have overlapped with daily workplace stressors, including pressure to meet performance standards, routine task management and juggling hard-to-manage tasks.

These issues related to the mental health of the company's employees will have a negative impact on productivity, as well as on personal and professional life.

Even if a good part of the companies have applied certain ways of working that do not require the physical presence in the company (telework, video conferencing, etc.):

- $85 \%$ of employees faced various challenges while working from home, the biggest factors being the impossibility of differentiating personal life from professional life $(42 \%)$ and facing increased mental health challenges, such as stress and anxiety $(32 \%)$;

- $40 \%$ of the company's employees reported that stress, anxiety or depression at work causes their productivity to decrease, and $44 \%$ said that these negative factors lead to a high rate of probability of making inappropriate decisions;

- $85 \%$ said that work-related stress, anxiety and depression affect their personal lives.

The survey found that $61 \%$ of people believe that their company should do more to protect the mental health of employees, and 39\% mentioned that they are provided with mental health services and assistance as a result of COVID- 19, to a sufficient extent. 


\section{Combating anxiety and depression at work with the help of appropriate risk management analysis}

Anxiety causes physical symptoms like tachycardia, shortness of breath, fatigue and sweating, emotional symptoms like sadness, sorrow, fear and excitement, and behavioral symptoms.[14]

Risk management involves the identification and assessment of risks, the identification and determination of the risk response in order to reduce the possibility of risks occurring, as well as the reduction of the consequences produced as a result of the materialization of risks. [9]

Risk analysis is the process by which risks are examined in more detail to determine the degree of risk and which of the identified risks are the most important to address. The risk analysis estimates the probability of occurrence, the average severity and the time period in which actions must be taken; similar risks are classified and risks are ranked. In order to support the risk analysis, a series of methods can be used, such as studies, test results, expert opinions, etc. For events with low probability and critical consequences, for which there are insufficient statistical data, methods of risk assessment can be applied, by which the risk is assessed with numerical values, by the product between the probability and the severity of the consequences. [10]

In the context in which the COVID-19 pandemic significantly affects business by suspending, diminishing and ceasing professional activity, efficient and fast communication is important in relation to the company's shareholders, which management must, on the one hand, regularly inform and with transparency, whenever is necessary, on any aspects or changes of the factual situation and on the other hand, to consult it in order to agree on the directions of action and in the case of multinationals, to act according to the group.

Taking into account the management analysis made within the company, it was found that there is a fairly common problem among employees due to the restrictions imposed by the COVID-19 pandemic, namely anxiety and stress at work. This increase in stress and anxiety has had a negative impact on mental health among employees in the company, causing a lack of balance between personal and professional life due to the fact that most were forced to work from home due to measures and restrictions imposed by pandemic and faced heavy management of routine tasks and juggling work tasks. A significant contribution was also the lack of basic measures that must be taken by any company to create a protective environment for employees so that they have access to all safety and hygiene standards required by current legislation.

In order to ensure a safe environment both physically and mentally, the company or employer has the obligation to provide each employee, in addition to the usual equipment and protective equipment, a number of elements necessary to combat risks such as: disinfectants, protective masks, the periodic control of the employee's physical and mental health by controlling the temperature, but also the intensification of the cleaning and disinfection procedures of all the spaces in which he carries out his activity.

Direct actions to eliminate and reduce the risk of anxiety and stress at work:

- Redesigning the activity: changing the content of the activity, enriching the tasks, alternating different tasks, eliminating fractional and simplified activities;

- Organizational measures: changing the way activities are organized, greater autonomy, assigning responsibilities, increasing the autonomy of teams of workers in managing tasks and work pace, rational organization of work and rest time, work schedule to allow activities extra-professional;

- Ergonomic measures and optimization of the work environment: control of occupational risks, optimization of environmental factors (microclimate, lighting, color, etc.) and workplace arrangement; 
- Workspace optimization: avoiding overloading the workplace or, conversely, working in isolation;

- Appropriate information on the work process, early information on any changes in the work process and the introduction of new objectives;

- Training workers in making decisions on organizational measures, working methods;

- Appropriate training and education: an education in the field of health, knowledge and recognition of risks and preventive measures;

- Measures to improve the psychosocial environment: staff participation in decision making, appreciation and encouragement from superiors, support from colleagues and subordinates, job maintenance, perspectives in professional promotion, etc., all creating a sense of individual control over the social environment;

- Social resources (social support): the social support network of the individual representing the set of interpersonal relationships of the individual that provides a positive emotional connection (friends, love, etc.), practical help (material, financial), information and assessments about the situation; it is very important how the individual appreciates the degree of social support the higher the appreciation, the greater the feeling of his own ability to control the situation and the less the negative effect of anxiety and stress. [11]

\section{Conclusions}

Globally, the COVID-19 pandemic has unprecedentedly caused a human health crisis. It has been responsible for a wide array of psychosocial problems, such as fear, anxiety, depression, stress, panic disorders, and social isolation. [12]

Following the analysis of risk management performed within the company, to reveal a major change in the mood and mental health of employees due to the effects imposed by the COVID-19 pandemic, the results of the study highlight the following conclusions:

- $\quad 83 \%$ of company employees would like their employer to provide the technology needed to help them maintain their mental health, including subscription-based access to health resources $(36 \%)$, proactive health monitoring tools $(35 \%)$, access to wellness or meditation applications $(35 \%)$ and computer programs designed to simulate conversations with human users answering health questions $(28 \%)$

- To reduce anxiety in the context of the COVID-19 pandemic, the employer should provide employees with free psychological counseling services;

- Establishing a support system for workers suffering from anxiety or stress. This system could consist of bosses asking workers how they feel more often, encouraging friendships between colleagues, making changes in the organization of work and work tasks, or introducing a program to support employees or employees their counseling service, as well as in contacting an occupational medicine service. It should also be borne in mind that employees may have experienced traumatic events, such as serious illness, or financial difficulties or problems in personal relationships;

- Improving the capacity of employees to better adapt to the pandemic situation through trainings aimed at stress management, relaxation methods, provision of spaces for sports activities, etc.;

- Maintaining the virtual connection between employees through existing technological means (teleconferencing, videoconferencing, etc.). These have an important role in maintaining the degree of mental and social health in the context of current restrictions. 


\section{Bibliography}

1. https://ro.wikipedia.org/wiki/COVID-19

2. https://www.ilo.org/wcmsp5/groups/public/---ed_dialogue/--act emp/documents/publication/wcms 748506.pdf

3. https://www.cdt-babes.ro/articole/coronavirus-infectia-COVID-19.php

4. https://www.unicef.org/moldova/articole/ce-trebuie-s $\% \mathrm{C} 4 \% 83-\% \mathrm{C} 8 \% 99$ tii-despre-vaccinul\%C3\%AEmpotriva-covid-19

5. https://sgg.gov.ro/new/wp-content/uploads/2018/07/Metodologia-de-management-al-riscurilor2018.pdf

6. www.startupcafe.ro

7. www.cdc.gov

8. www.healthinaging.org

9. https://agora.md/stiri/83620/analiza-bloomberg-vom-scapa-de-pandemie-in-sapte-ani-daca-ratade-vaccinare-se-va-pastra-la-fel

10. https://ro.wikipedia.org/wiki/Managementul_riscului

11. R.I. Moraru, Securitate și sănătate în muncă: Tratat Universitar (Petroșani, 2013)

12. Gökmen Arslan, Murat Yldirim, Ahmet Tanhan, Metin Buluș, Kelly-Ann Allen, Coronavirus Stress, Optimism-Pessimism, Psychological Inflexibility, and Psychological Health: Psychometric Properties of the Coronavirus Stress Measure (Turkey, June 2020)

13. Getachew Alemkere Kolech, Coronavirus disease and its management (May 2021)

14. H. Mustafa Paksoy, Yakup Durmaz, Filiz Çopuroğlu, B. Dilek Özbezek, The Impact of Anxiety Caused by COVID-19 on Consumer Behaviour (October 2020)

15. Ewa Rusyan, Agnieszka Mielczarek, Agnieszka Kapała, Kamil Adamczyk, Robert Piec, Barbara Szykuła- Piec, Level of anxiety caused by the coronavirus (COVID-19) pandemic among dentists in Poland (August 2020)

16. Zafir Mohd Makhbul, Zainab Rawshdeh, Mental stress post-COVID-19 (March 2021) 